Cell Research, (2001); 11(1):61-67

\title{
Overexpression of $\gamma$-aminobutyric acid transporter subtype I leads to susceptibility to kainic acid-induced seizure in transgenic mice
}

\author{
MA Ying HuA ${ }^{1}$, Jia Hua HU ${ }^{1}$, Wen Juan ZHAO ${ }^{1}$, Jian FEI ${ }^{1, *}$, Yun YU1, Xiao Gang ZHOU ${ }^{1}$, Zhen \\ Tong $\mathrm{MEI}^{2}$, Li He GUO ${ }^{1, *}$ \\ 1 Institute of Biochemistry and Cell Biology, Shanghai Institutes for Biological Sciences, Chinese Academy \\ of Sciences, Shanghai 200031, China \\ 2 Shanghai Institute of Physiology, Chinese Academy of Sciences, Shanghai 200031, China
}

\begin{abstract}
$\gamma$-aminobutyric acid (GABA) is the principal inhibitory neurotransmitter, and the GABAergic synaptic transmission is normally terminated by the rapid uptake through GABA transporters. With transgenic mice ubiquitously overexpressing GABA transporter subtype I (GAT1), the present study explored the pathophysiological role of GAT1 in epileptogenesis. Though displaying no spontaneous seizure activity, these mice exhibit altered electroencephalographic patterns and increased susceptibility to seizure induced by kainic acid. In addition, the $\mathrm{GABA}_{A}$ receptor and glutamate transporters are up-regulated in transgenic mice, which perhaps reflects a compensatory or corrective change to the elevated level of GAT1. These preliminary findings support the hypothesis that excitatory and inhibitory neurotransmission, and seizure susceptibility can be altered by neurotransmitter transporters.
\end{abstract}

Key words: $\gamma$-aminobutyric acid transporter, seizure, susceptibility, kainic acid, electroencephalography, transgenic mice

\section{INTRODUCTION}

g-aminobutyricacid(GABA), amajorinhibitoryneurotransmitterinvertebratebrain,inducesneuronalinhibition via GABA receptors. A deficiency of GABAergic inhibition has been hypothesized to be a principal factor in the pathogenesis of epilepsy[1]. GABA transporters are important components of the GABAergic system, andfunctioninparttoterminatetheGABAtransmission through rapid re-uptake of GABA into the presynaptic neurons and surroundingglial cells[2]. GABA transporters play a critical rolein regulation of the magnitude and duration of GABA's action and may also mediate the release of GABA into the extracellular space in a $\mathrm{Ca}^{2+}$-independent manner[3]. GABA transporters also have a pathophysiological role. It has been

\footnotetext{
* Corresponding author: Prof. Lihe Gao. Dr. Jian Fei,

Fax:(86)-21-64331090, E-mail: Fei@guomai.sh.cn

Received Nov-8-2000 Revised Dec-26-2000 Acceped Jan-18-2001
}

suggested that alterations in GABA and glutamate transporters may be related to epileptogenesis and seizure propagation[4]. In patients with temporal lobe epilepsy, During et al have shown that the function of GABA transporter subtypeI (GAT1), the predominant neuronal GABA transporter, was impaired in epileptogenic hippocampi[5]. Recently, the antiepileptic effects of tiagabine (TGB), which selectively inhibits GABA uptake mediated by GAT1, have been demonstrated in various animal models of epilepsy[6]. Hence, altered GAT1 function is possibly involved in the pathology of certain types of epilepsy. Here, we preliminarily addressed this question employing GAT1overexpressed.transgenic mice.

\section{MATERIALSANDMETHODS}

\section{Animals}


Transgenic mice that harbor the murine GAT1 (m GAT1) cDNA have been previously produced and identified (data not shown). A full length $\mathrm{cDNA}$ coding for mGAT1 that screened from the $\lambda$ phage murine brain cDNA library was cloned into the EcoR I and Apa I site of pcDNA3, under the control of human cytomegalovirus (HCMV) promoter/enhancer. Thisconstruct,linearized withNruIandTth111 Iand subsequently gel-purified, was microinjected into the pronuclei of fertilized eggs of (C57BL/6J) F1 hybridmice (JacksonLaboratory). Polymerase chain reaction (PCR) and Southern-blot analysis were carried out with tail DNA to verify the integration of variable copy numbers of transgene into the genomes of founder mice and their progenies. Semi-quantitative reverse transcription-PCR (RT-PCR) and Northern-blot analysis of whole RNA samples, extracted from a variety of tissues, were used to characterize the expression pattern of the transgene. Age-matched wild-type littermates were used as control in the present study. All mice were housed in groups (2-5 mice percage) intemperature-andhumidity-controlledenvironment with a 12 -h light/12- $\mathrm{h}$ dark rhythm, and allowed free access to food and water.

\section{Determinationofneurotransmittersuptakeinsynapto- somes}

Whole brain from 4-mon-old mice, sacrificed by decapitation, were rapidly isolated and subsequently homogenized in $0.32 \mathrm{M}$ sucrose. Crude synaptosomes were prepared according to Hornsby et al[7]. The protein contents of the samples were measured using the method of Lowry.

Synaptosomes $(1.0 \mathrm{mg} / \mathrm{ml}$ protein, final volume $600 \mu \mathrm{l} /$ tube $)$ were pre-incubated in the artificial cerebrospinal fluid (aCSF) buffer (composition in mM: $\mathrm{NaCl} 126.6$; $\mathrm{NaHCO}_{3} 27.4 ; \mathrm{KCl} 2.4$; $\mathrm{KH}_{2} \mathrm{PO}_{4} 0.49 ; \mathrm{CaCl}_{2} 1.2 ; \mathrm{MgCl}_{2} .6 \mathrm{H}_{2} \mathrm{O} 0.83 ; \mathrm{Na}_{2} \mathrm{HPO}_{4}$ 0.49; Dglucose 7.1 ; gassed with $95 \% \mathrm{O}_{2} / 5 \% \mathrm{CO}_{2} ; \mathrm{pH} 7.2-7.4$ ) for $5 \mathrm{~min}$ at $37^{\circ} \mathrm{C}$. After pre-incubation, uptake was initiated by the addition of cold and tritiated compounds $\left({ }^{3} \mathrm{H}-\mathrm{GABA}, 98 \mathrm{Ci} / \mathrm{mmol} ;{ }^{3} \mathrm{H}\right.$-glutamate, $53 \mathrm{Ci} / \mathrm{mmol} ;{ }^{3} \mathrm{H}$-serotonin, $97 \mathrm{Ci} / \mathrm{mmol}$;Amersham).

For time-coursestudies, thefinal concentration of thecompound was $40 \mathrm{nM}, 10 \%$ of which was tritiated. For saturation analysis, the final incubation time was 5 minfor all compounds. Theamount of the tritiated compound was kept constant $(4.0 \mathrm{nM})$ and the different compound concentrations $(0.04-40 \mu \mathrm{M})$ were obtained by adding varying amounts of the corresponding unlabelled compounds. Samples incubated for 0 min served as blanks. Uptake was terminated by vacuum filtration through aWhatman glass-fiber filter with subsequent rinsing with cold incubation buffer, the compound content of the filter was assayed by liquid scintillation counting, taking dilution factors into account.

Thestraight regression lines were fitted to the experimental data and employed for the estimation of transport parameters.

\section{Electroencephalographicrecordingandanalysis}

At 2-3 mon of age, mice were anesthetized by intraperitoneal injection with $10 \%$ chloral hydrate $(2.5 \mathrm{ml} / \mathrm{kg}$ body weight $)$, and then positionedinastereotaxicapparatus. Micewere then bilaterally implanted with two stainless electrodes fixed in the skull on the frontal and the parietal portions of the dura mater. The reference elec- trode was implanted in the nasal bone. When the mice were recovered from anesthesia, electroencephalograms (EEGs) were recorded continuously for $4 \mathrm{~h}$ using a Grass polygraph. EEG signals were digitized at a sampling rate of 1.0-30 HZ and determined by a fast Fourier transform, and then stored in computer for off-line spectral poweranalysis.

\section{Kainicacid-inducedseizure}

After EEGs recording described above, mice received a single intraperitoneal injection with kainic acid $(20 \mathrm{mg} / \mathrm{kg}$ body weight, Sigma). Then, EEGs were immediately recorded again and lasted until the end of status epilepticus or death.

\section{Comparative reverse transcription-polymerase chain reaction $(R T-P C R)$ analysis}

Whole brain was removed from 3-mon-old mice after cervical dislocation. Total RNA was extracted with Tizol reagent (GIBCO) as detailed by the manufacturer's protocols. Reverse transcription (RT) was subsequently performed with GIBCO kit using a random primer. The equal aliquots of each RT-conducted mixture were employed for PCR amplification with the following primer-pairs.GAT1: ACCAAGCTTAGGCTGCAAAGCTGCTG, AGGCCTTT GAACATGGGCGCCAG; $\mathrm{GABA}_{A}$ receptor(degenerateprimers):ACC (A/G)ACA(T/C)GTT(G)CTA(C/G)ACC(A/T)ATGAC,G(C)CCAG(A) $\operatorname{TAA}(\mathrm{G}) \operatorname{ACT}(\mathrm{C} / \mathrm{T}) \mathrm{AG}(\mathrm{A} / \mathrm{C}) \mathrm{A}(\mathrm{G}) \mathrm{TTG}(\mathrm{A}) \mathrm{AA} ; \mathrm{GLT}-1$ : A G A G C T G C C C G T T A A T A C C , T T CAA GAA T T G G C T GA GAATCGG; GAPDH : ACGACCCCTTCATTGACC, AGACACCAGTAGACTCCACG. All reactions were carried out as follows: $94^{\circ} \mathrm{C}$ for $45 \mathrm{sec}, 64^{\circ} \mathrm{C}$ for $60 \mathrm{sec}$, and $72{ }^{\circ} \mathrm{C}$ for $120 \mathrm{sec}$. Relative intensities of the resultant PCR fragments within the series were estimated with a PhosphorImager analysis (Molecular Dynamic).

\section{RESULTS}

\section{Increased GABA uptake in synaptosomes from transgenic mice}

We previously characterized the overexpression of GAT1 in the brain of transgenic mice (data not shown). To explore whether the elevated level of GAT1 would promote GABA uptake, we determined the GABA uptake in nerve terminals. The time-course analysis indicates that the synaptosomal accumulation of GABA was time-dependent and reached a maximum at $5 \mathrm{~min}$. Transgenic mice exhibited evidently enhanced GABA uptak compared with wild-type littermates (Fig 1). Significantly increased Vmax value in transgenic mice compared to that controls (Tab 1a), which was revealed by the saturation analysis, strongly suggesting that the enhanced GABA uptsake may be attrib- 
uted to the elevated level of neuronal GABA transporters, since the Vmax value probably reflects the density of transporter sites in the nerve terminals. $\mathrm{Km}$ values measured here are close to the reported range for the cloned GAT1 transporter of 3-11 $\mu \mathrm{M}$ [8]. Collectively, the above results further confirmed that the overexpression of GAT1 authentically enhanced the GABA uptake. It is conceivable that there was no significant difference in $\mathrm{Km}$ value between transgenic mice and normal mice.

\section{Electroencephalographic alterations in transgenic mice}

Spontaneous Electroencephalograms (EEGs) in transgenic mice and wild-type littermates were recorded at 2-3 mon of age. The EEG pattern in transgenic mice was characterized by low amplitude and high frequency waves (Fig 3a). The collected computerized EEG signals were examined for power analysis of cerebral discharges. The total power of cerebral discharges in transgenic mice was only about $50-60 \%$ of wild-type controls, which indicates that the cerebral discharge in transgenic mice was significantly reduced (Fig 2a). Furthermore, spectral analysis of the relative power distribution at various frequency bands of cerebral discharges statistically revealed that the transgenic mice exhibited decreased 1.0-3.5 HZ and

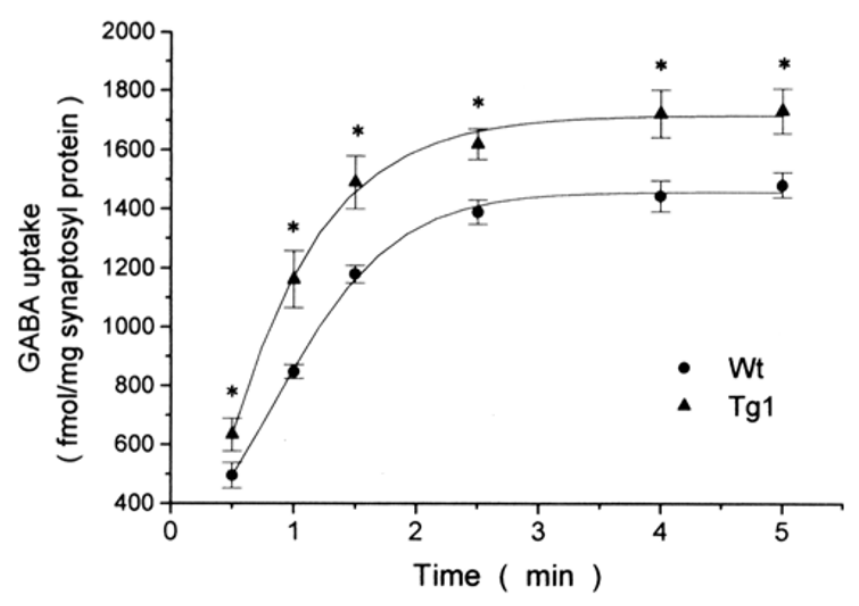

Fig 1. Time courses of ${ }^{3} \mathrm{H}-\mathrm{GABA}$ uptake in synaptosomes from 3-mon-old transgenic (Tg1) and wild-type (Wt) mice. Synaptosomes were incubated at $37^{\circ} \mathrm{C}$ in the presence of $40 \mathrm{nM}$ GABA, $10 \%$ of which was tritiated. Values were given as mean \pm s.e.m. $(n=7$ mice $)$. Single asterisk indicates significantdifferenceatP $<0.01$; student'st-test. increased 13.0-30.0 HZ cerebral discharge compared with wild-type mice (Fig $2 \mathrm{~b}$ ). It might reflect the more fast electroencephalographic activities in transgenic mice than thatinnormalmice.

\section{Increasedsusceptibilitytokainicacid-inducedseizuresin transgenicmice}

Although no spontaneous seizure-like behavioral abnormalities were observed in transgenic mice, pharmacological challenge with kainic acid (KA), a convulsant agent extensively used to induce epilepsy in animal, revealed that the susceptibility of these mice to seizures is evidently increased. A single intraperitoneal injection of $\mathrm{KA}$, at the dosage of $20 \mathrm{mg} / \mathrm{kg}$ body weight, produced the following sequence of events in both transgenic lines: after a latency period (approximately $20-30 \mathrm{~min}$ ), the animals showed whole-body twitches, followed by generalized clonic seizures, subsequently progressed to a tonic stage with caudal extension of all four limbs and arrest of respiration, finally led to death at approximately 45 to 120 min after KAinjection. However, under the same dosage, wild-type mice only shortly exhibited moderate clonic seizures at approximately $40 \mathrm{~min}$, and recovered 4 to $6 \mathrm{~h}$ after KA administration. According to the Racine scale [9], seizure episodes induced in transgenic mice attained to grade 5 (severe tonic clonus), whereas it in wild-type mice generally reached to grade 4 (moderate forelimb clonic activity and rearing with clonus). In addition, EEG recordings also indicated that epileptic bursts associ-

Tab 1. Kinetic analysis of ${ }^{3} \mathrm{H}-\mathrm{GABA}$ (a) and ${ }^{3} \mathrm{H}$-glutamate (b) uptake in synaptosomes from transgenic (Tg1) and wild-type (Wt) mice.

a

\begin{tabular}{|c|c|c|c|}
\hline & $\mathrm{Wt}$ & Difference & \\
\hline \multicolumn{2}{|c|}{$\mathrm{Km} 2.51 \pm 0.41$} & 0.49 & \\
\hline Vmax & $15.8 \pm 1.6$ & $21.6 \pm 2.2$ & $\mathrm{P}<0.01$ \\
\hline
\end{tabular}

\begin{tabular}{|c|c|c|c|}
\hline & $\begin{array}{ll}\mathrm{Wt} & \mathrm{Tg}\end{array}$ & Difference & \\
\hline $\mathrm{Km}$ & $17.1 \pm 2.7$ & $16.5 \pm 4.7$ & $\mathrm{~N}$ \\
\hline Vmax & $136.0 \pm 14.7$ & $185.7 \pm 25.6$ & $\mathrm{P}<0.01$ \\
\hline
\end{tabular}

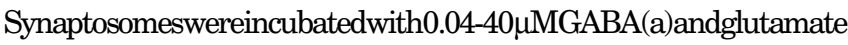
(b),respectively,for5min.Resultingconcentration-uptakecurveswere then analyzed togive Km and Vmax values. Values given were mean \pm s.e.m. of 4 separate experiments. $\mathrm{Km}$ values are in $\mu \mathrm{M}$, and $\mathrm{Vmax}$ valuesareinpmol/mgsynaptosylprotein/min.Ndenotesnosignificant differencebetweenwild-typeand transgenicmice. 

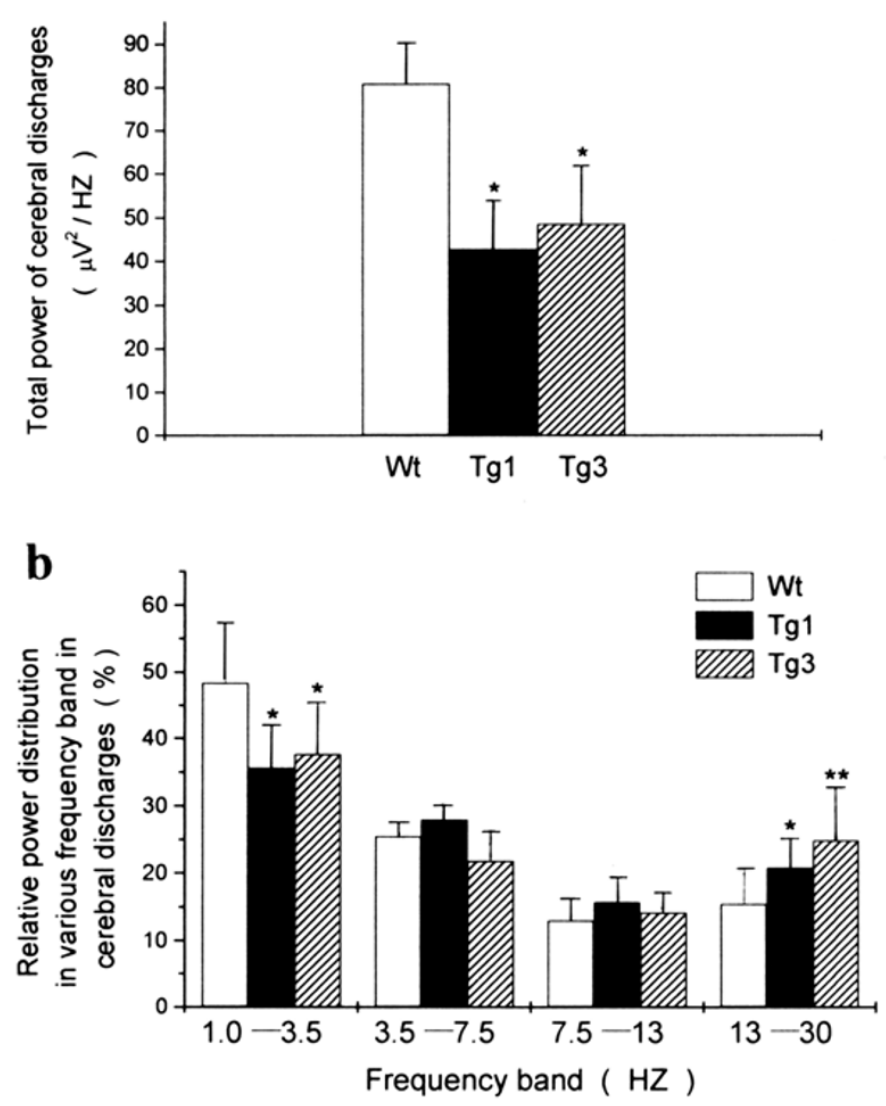

Fig 2. a. Total power of cerebral discharges, during basal conditions, in two independent lines of transgenic mice ( $\mathrm{Tg} 1$ and Tg3) and wild-type littermates (Wt). b. Relative power distribution at various frequency bands, expressed as a percentage of the total power of cerebral discharges. Data expressed as mean \pm s.e.m. (Wt, $\mathrm{n}=7$ mice; $\mathrm{Tg} 1, \mathrm{n}=8$ mice; $\mathrm{Tg} 3, \mathrm{n}=$ 6 mice). Single asterisk and double asterisks indicate significant differencefromcontrolmiceinvariousgroupsat $\mathrm{P}<0.05$ and $\mathrm{P}<0.01$, respectively;student'st-test.

ated with behavioral changes were detected in transgenic mice, whereas no epileptiform discharges were observed in controls (Fig $3 b$ ).

Up-regulation of $G A B A_{A}$ receptor and glutamate transporters in transgenic mice

Although the GABAergic neurotransmission might be disrupted by the abnormal elevated expression of GAT1, transgenic mice displayed no behavioral manifestations of seizure activity during postnatal development. We therefore speculate that some compensative mechanisms probably occurred in these mice. Since many studies suggested that the functional impairment of GABAA receptor or glutamate transporters may results in epilepsy[10-12], we evaluated the expression of two important subunits ( $\alpha 1$ and $\beta 3$ ) of $\mathrm{GABA}_{A}$ receptor, and GLT-1, a widely distributed astrocytic glutamate transporter, by semi-quantitative RTPCR analysis. As shown in Fig 4, GABA $A_{A}$-specific degenerate primers simultaneously yielded a 456bp fragment for $\alpha 1$ subunit and a 564-bp fragment for b3 subunit of the GABAA receptor, and GLT1 -specific primers yielded a 1846 -bp fragment. All resultant products were subsequently verified by sequencing analysis (data not shown). Quantitative analysis of these fragments compared with the internal GAPDH-control by Image Quant program indicated that the expression level of the $\alpha 1$ and $\beta 3$ subunits of $\mathrm{GABA}_{A}$ receptor, and also the GLT-1, were evidently up-regulated in transgenic mice. Furthermore, time-course determination in synaptosomal uptake indicated that the glutamate uptake in transgenic mice was significantly enhanced than that in wild-type mice (Fig 5a). However, the serotonin uptake, monitored for unrelated control, only showed a statistically insignificant reduction in transgenic mice compared with wild-type littermates (Fig 5b). Additionally, kinetic analysis further revealed that the transgenic mice had higher glutamate uptake Vmax value than did the controls (Tab 1b).

\section{DISCUSSION}

Transgenic mice were previously generated with GAT1 overexpression in the brain and a variety of peripheral tissues. Increased GABA uptake in crude synaptosomes further confirms that the excessive expression of GAT1 in transgenic mice is functionally significant. Though developing no spontaneous epileptic seizure, these mice exhibited significant electroencephalographic alterations and increased susceptibility to kainic acid-induced seizure. It indicates that there is some abnormality in brain function of transgenic mice.

A deficiency of GABAergic inhibition mediated 


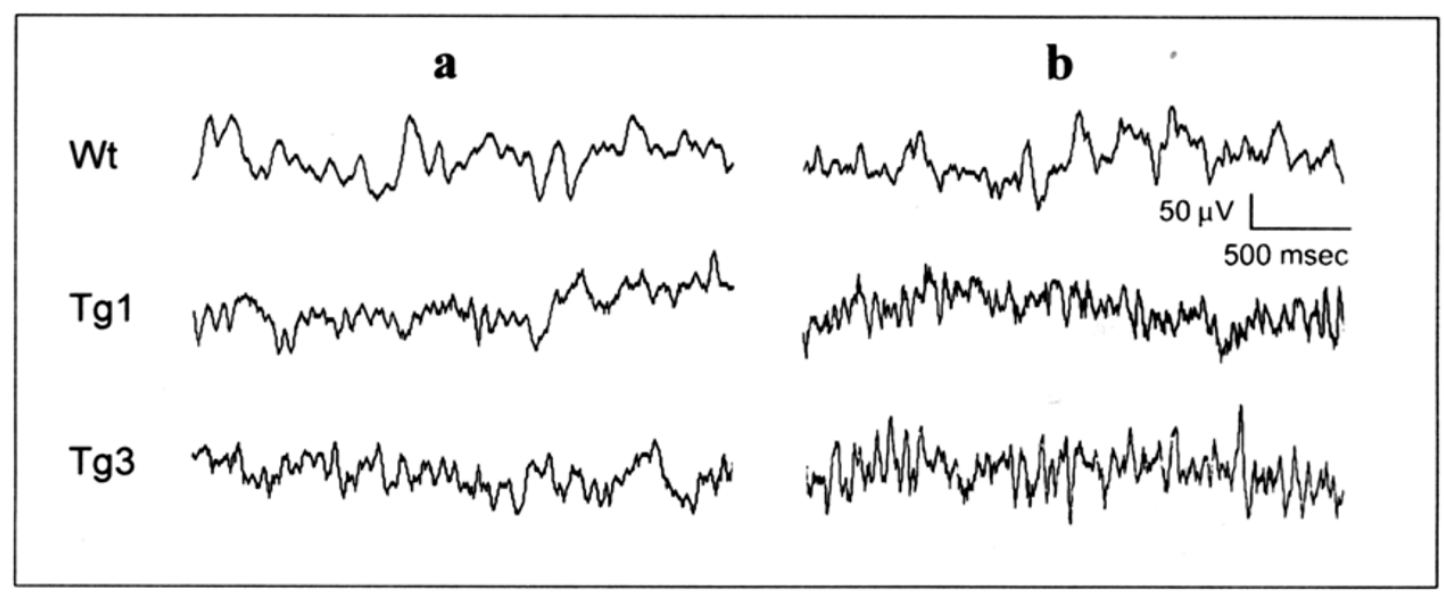

Fig 3. Electroencephalographic recordings of transgenic (Tg1 and Tg3) and wild-type (Wt) mice before (a) and after (b) kinaic acid administration. Transgenic mice exhibited more high-frequency discharges compared with control mice (a). Note the sharpwaveburstsin transgenicmiceafterkinaicacidinjection(b).

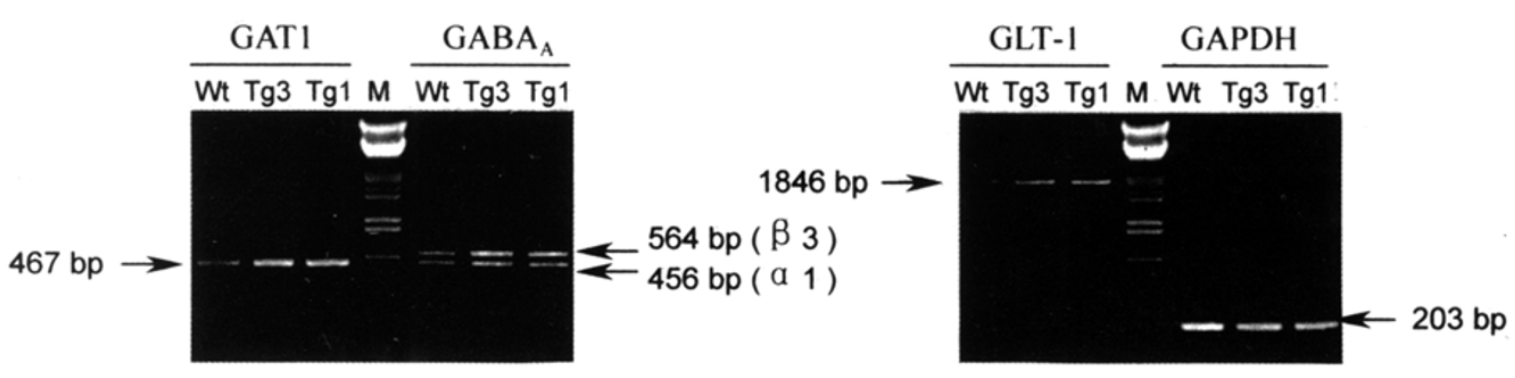

Fig4. Semi-quantitativeRT-PCRanalysisoftheexpressionofGAT1, $\alpha 1$ and $\beta 3$ subunitsofGABA $A_{A}$ receptor, andGLT-1inthebrainof3-monoldwild-type(Wt)andtransgenic(Tg1andTg3)mice.GADPHmRNAwasservedasaninternalstandard.ThesizesofresultantPCRfragmentsare indicatedbyarrows.

$\mathbf{a}$

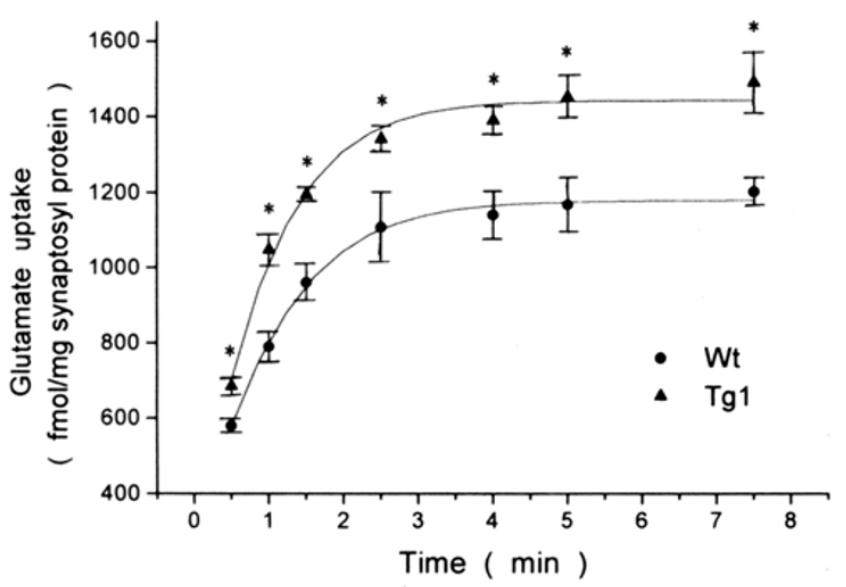

b

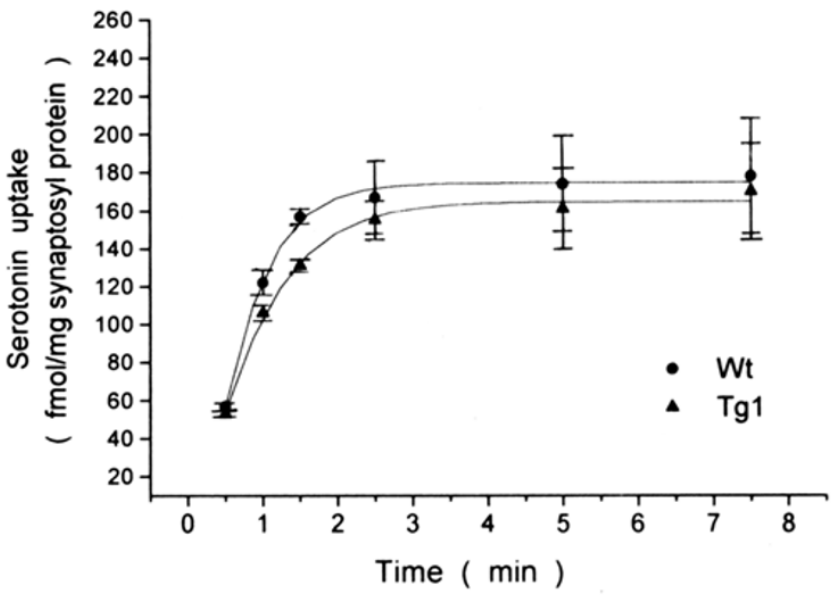

Fig5. Timecourse of ${ }^{3} \mathrm{H}$-glutamate(a) and ${ }^{3} \mathrm{H}$-serotonin(b) uptakeinsynaptosomesfrom3-mon-oldtransgenicmice(Tg1)andwild-type(Wt). Synaptosomes wereincubatedat $37^{\circ} \mathrm{Cin}$ thepresenceof $40 \mathrm{nMglutamateand} \mathrm{serotonin,} \mathrm{respectively.} \mathrm{Valuesweregivenasmean} \pm$ s.e.m. $(\mathrm{n}=7$ mice).SingleasteriskindicatessignificantdifferenceatP $<0.01$; student'st-test 
via the $\mathrm{GABA}_{A}$ receptor complex has for a long time been suspected to be a major factor in epileptogenesis. $\mathrm{GABA}_{A}$ receptors are constructed from a number of different subunits, designated as $\alpha, \beta, \gamma, \delta$, and $\varepsilon$ subunit. In the mammalian CNS, $\alpha, \beta, \gamma$, subunit exists as 6,3 , and 4 subtypes, respectively. Failure in switching from embryonic GABA $_{A}$ a subunits $(\alpha 2, \alpha 3$ and $\alpha 5)$ to the predominant subunit of the adult brain $(\alpha 1)$ was suggested to underlie temporal lobe epilepsy[12]. Mice lacking the $\mathrm{GABA}_{\mathrm{A}}$ receptor $\beta 3$ subunit are subject to an evolving epileptogenic condition that culminates in spontaneous seizures[11]. Conceptually, the upregulation of the $\alpha 1$ and $\beta 3$ subunits of GABAA receptor would enhance the synaptic inhibition in transgenic mice.

On the other hand, alterations in the balance of excitatory and inhibitory synaptic interactions is thought to be involved in epileptogenesis[13]. It has been known that GLT-1, a subtype of astroglial glutamate transporters, contributes to the maintenance of extracellular glutamate concentrations at low levels, and without its action, glutamate levels rise sufficiently to cause epilepsy and cell death[10]. Therefore, the up-regulation of GLT-1 might suggest that the excitatory synaptic transmission was altered in transgenic mice. In addition, increased glutamate uptake in synaptosomes indicated that the neuronal glutamate transporters (EAAC1 and EAAT4) were probably also up-regulated, since synaptosomes are isolated nerve terminals, and only neuronal uptake proteins would be expected to mediate synaptosomal uptake[14]. An opinion suggested that the up-regulation of $\mathrm{GABA}_{\mathrm{A}}$ receptor and glutamate transporters might represent a compensatory or corrective change to the overexpression of GAT1, and contributed to maintain the balance between excitatory and inhibitory synaptic activities in transgenic mice. But this balance is subject to disruption, as evidenced by their increased susceptibility to kainic acid-induced seizure. It's noteworthy that kainic acid exerts its effect by inhibiting the GABA release through the activation of kainate-selective receptor at presynaptic GABAergic terminals[15].

Recent studies indicate that transporters may work in reverse direction, and thereby release transmitters into the extracellular space via a nonvesicular, $\mathrm{Ca}^{2+}$-independent manner if there is a loss of ionic gradients or membrane potentials[5], [16]. Neuronal depolarization during seizure, which commonly reaches -40 or $-30 \mathrm{mV}$, is sufficient to reverse GABA transport[17]. Hence, it's possible that the overexpression of GAT1 would faci- litate the $\mathrm{Ca}^{2+}$ independent GABA release during seizureactivity, and may contribute to suppress the propagation of seizure in transgenic mice. However, enhanced susceptibility to kainic acid-induced seizure suggests that the influence possibly exerted by the increased GABA release may be very limited and less effective in challenging conditions. Additional experiments are required tofully characterize the extracellular GABAand glutamatelevels in both basal and seizure conditions.

\section{ACKNOWLEDGEMENTS}

WethankMr.WenXingZHOUforliquidscintillation counting, Mr. RuoWangZENG for routineanimal care, and colleagues in the Neurobiology Laboratory of Shanghai Medical University for assistance in EEG recording and analysis.

\section{REFERENCES}

[1]KarleJ,Woldby DP,ElsterL.etal.Antisenseoligonucleotideto GABA(A)receptor $\gamma 2$ subunitinduceslimbicstatusepilepticus.J Neurosci Res 1998; 54: 863-9.

[2] Schloss P, Puschel AW, Betz H. Neurotransmitter transporters: new members of known families. Curr Opin Cell Biol 1994; 6:595-9.

[3] Levi G, Raiteri M. Carrier-mediated release of neurotransmitters. Trends Neurosci 1993; 16:415-8.

[4] Akbar MT, Rattray M, Williams RJ, Chong NW, Meldrum BS. Reduction of GABA and glutamate transporter messenger RNAs in the severe-seizure genetically epilepsyprone rat. Neuroscience 1998; 85:1235-51.

[5] During MJ, Ryder KM, Spencer DD. Hippocampal GABA transporter function in temporal-lobe epilepsy. Nature 1995; 376:174-77.

[6] Morimoto K, Sato H, Yamamoto Y, Watanabe T, Suwaki H. Antiepileptic effects of tiagabine, a selective GABA uptake inhibitor, in the rat kindling model of temporal lobe epilepsy. Epilepsia 1997; 38:966-74.

[7] Hornsby CD, Barnes JM, Barnes NM, Champaneria S, Costall B, Naylor R. Pharmacological comparison of the rat and guinea-pig cortical high affinity 5-hydroxytryptamine uptake system. Biochem Pharmacol 1992; 43:1865-8.

[8] Guastella J, Nelson N, Nelson H. et al. Cloning and expression of a rat brain GABA transporter. Science 1990; 249:1303-6.

[9] Racine RJ, Modification of seizure activity by electrical 
stimulation: II. Motor seizure. Electroencephalogr. Clin Neurophysiol 1972; 32:281-94.

[10] Tanaka K, Watase K, Manab T, et al. Epilepsy and exacerbation of brain injury in mice lacking the glutamate transporter GLT-1. Science 1997; 276:1699702 .

[11] Delorey TM, Handforth A, Anagnostaras S. et al. Mice lacking the beta 3 subunit of the GABAA receptor have the epilepsy phenotype and many of the behavioral characteristics of Angelman syndrome. J Neurosci 1998; 18: 8505-14.

[12] Poulter MO, Brown LA, Tynan S, Willick G, William R, Mclntyre DC. Differential expression of a1, a2, a3, and a5 GABAA receptor subunits in seizure-prone and seizure-resistant rat models of temporal lobe epilepsy. $\mathrm{J}$ Neurosci 1999; 19:4654-61

[13] Colom LV, Saggau P. Spontaneous interictal-like activ- ityoriginatesinmultipleareas oftheCA2-CA3regionofhippocampalslices.JNeurophysiol 1994; 71:1574-85.

[14] Sutch RJ, Davies CC, Bowery NG. GABA release and uptake measured in crude synaptosomes from Genetic Absence Epilepsy Rats from Strasbourg (GAERS). Neurochem Int 1999; 34:415-25.

[15] Rodriguez-Moreno A, Herreras O, Lerma J. Kainate receptors presynaptically downregulate GABAergic inhibition in the rat hippocampus. Neuron 1997; 19:893901.

[16] Matherm GW, Mendoza D, Lozada A et al. Hippocampal GABA and glutamate transporter immunoreactivity in patients with temporal lobe epilepsy. Neurology 1999; 52:453-72.

[17] Meldrum B, Epilepsy. Taking up GABA again. Nature 1995; 376:122-3. 